\title{
Utilização da taboa (typha domingensis) e papiro (cyperus papyrus) em leitos cultivados com efluente suíno originário da biodigestão anaeróbia e decantação
}

A remoção biológica de nutrientes com a utilização de plantas aquáticas vem sendo utilizada para melhorar a qualidade das águas residuárias, principalmente as originárias da suinocultura. Este trabalho teve por objetivo avaliar os parâmetros físico-químicos e microbiológicos do efluente suíno (ES) originário da biodigestão anaeróbia e decantação com a utilização de Taboa (Typha dominigensi) e Papiro (Cyperus papyrus) em leitos cultivados experimentais. Foram construídos quatro sistemas experimentais com duas repetições cada um, sendo: a) tratado (taboa), b) tratado (papiro), c) tratado (papiro e taboa), e, d) controle (somente o efluente). O ES teve um tempo de detenção hidráulica de sete dias abastecidos semanalmente. Foram avaliados os seguintes parâmetros físico-químicos: pH, sólidos totais (ST), nitrogênio total (NT) e fósforo total (FT). Foram também avaliados os parâmetros microbiológicos com a pesquisa de coliformes totais e termotolerantes. Os sistemas de cultivo de efluente suíno proveniente da biodigestão anaeróbia e decantação tratados com taboa (Typha domingensis) e papiro (Cyperus papirusl) não foi capaz de reduzir as bactérias do grupo coliforme total, as bactérias do grupo coliforme termotolerantes, apresentaram redução em todos os sistemas analisados. A variação de $\mathrm{pH}$ foi mínima, mantendo-se na faixa da alcalinidade, assim como os valores de sólidos totais. O nitrogênio total obteve redução significativa na primeira semana do experimento. Os valores de fósforo total apresentaram altas taxas de remoção, o papiro atuando sozinho apresentou melhor capacidade de assimilação deste nutriente.

Palavras-chave: Suinocultura; Plantas Aquaticas; Bioremediadores.

\section{Use of taboa (typha domingensis) and papirus (cyperus papyrus) in cultivaded beds with swine effluent provenient of anaerobic biodigestion and decantation}

\begin{abstract}
The biological removal of nutrients with the use of aquatic plants has been used to improve the quality of wastewater, especially those originating from swine. The objective of this work was to evaluate the physico-chemical and microbiological parameters of swine effluent (ES) originating from anaerobic biodigestion and decantation using Taboa (Typha dominigensi) and Papiro (Cyperus papyrus) in experimental beds. Four experimental systems with two replicates were constructed: a) treated (taboa), b) treated (papyrus), c) treated (papyrus and taboa), and d) control (effluent only). The ES had a seven-day hydraulic holding time supplied weekly. The following physico-chemical parameters were evaluated: $\mathrm{pH}$, total solids (ST), total nitrogen (NT) and total phosphorus (FT). Microbiological parameters were also evaluated with total and thermotolerant coliforms. The systems of swine effluent culture derived from anaerobic and decanting biodigestion treated with taboa (Typha domingensis) and papyrus (Cyperus papirusI) were not able to reduce the bacteria of the total coliform group, the bacteria of the thermotolerant coliform group, showed reduction in all the analyzed. The $\mathrm{pH}$ variation was minimal, remaining in the alkalinity range, as well as the values of total solids. Total nitrogen obtained a significant reduction in the first week of the experiment. Total phosphorus values presented high removal rates, papyrus acting alone presented better assimilation capacity of this nutrient.
\end{abstract}

Keywords: Swine Culture; Aquatic Plants; Bioremediators.

Topic: Microbiologia Agrícola e Ambiental

Reviewed anonymously in the process of blind peer.

Giovanni Fatobene

Instituto Federal de São Paulo, Brasil

http://lattes.cnpq.br/3326320558903711

giovanni.fatobene10@gmail.com

Francisco Rafael Martins Soto ic

Instituto Federal de São Paulo, Brasil

http://lattes.cnpq.br/8697221494886208

http://orcid.org/0000-0002-7483-242X

sotofrm@ifsp.edu.br

Ricardo Augusto Rodrigues

Instituto Federal de São Paulo, Brasi

http://lattes.cnpq.br/6697645400414051

ricardo.augusto@ifsp.edu.com.br

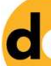

DOI: 10.6008/CBPC2179-6858.2019.002.0004
Received: $12 / 02 / 2019$

Approved: 28/03/2019
Ana Carolina da Silva Vaz Curado de Aguiar

Instituto Federal de São Paulo, Brasil

http://lattes.cnpq.br/1445676612545541

anacarolinavazcurado@gmail.com
Referencing this:

FATOBENE, G.; SOTO, F. R. M.; RODRIGUES, R. A.; AGUIAR, A. C. S. V. C.. Utilização da taboa (typha domingensis) e papiro (cyperus papyrus) em leitos cultivados com efluente suíno originário da biodigestão anaeróbia e decantação. Revista Ibero Americana de Ciências Ambientais, v.10, n.2, p.35-44, 2019. DOI:

http://doi.org/10.6008/CBPC2179-6858.2019.002.0004 


\section{INTRODUÇÃO}

Há mais de dez anos, o Brasil ocupa a quarta posição no ranking mundial de produção de carne suína, sendo a China, União Europeia e Estados Unidos os maiores produtores (MARÇAL et al., 2016). Um dos maiores investimentos que os produtores realizaram para melhor crescimento da suinocultura no país foi na evolução genética dos animais. Com isto foi possível à redução de $31 \%$ da gordura dos animais, $10 \%$ do colesterol e $14 \%$ de calorias, tornando a carne suína nacional mais magra e nutritiva para o consumo (FERNANDES et al., 2009). Em decorrência desses resultados foi registrado o aumento na produção de cerca de 13 a 15\% desde o período de 2007 a 2013 (ANUNCIATO et al., 2016).

Infelizmente muito se preocupou em atender à necessidade do mercado deixando de lado a preocupação do gerenciamento dos dejetos, o que acarretou inúmeros problemas ambientais como contaminação do solo, água e lençóis subterrâneos (KUNZ et al., 2005). Segundo estimativas, a produção suinícola é uma das que mais podem causar impactos significativos no meio ambiente. Muitos produtores utilizam o efluente suíno (ES) como fertilizante pelo seu alto teor de nutrientes e matéria orgânica, entretanto com o modelo de criação atual, em média é gerado de 7,0 a 8,0 L de dejetos suínos por dia, o que pode se tornar prejudicial caso ocorra o descarte inadequado dos dejetos no meio ambiente (BROETTO et al., 2015).

No Brasil, a Resolução no 357/2005 do CONAMA classifica os corpos d'água, estabelecendo os padrões de qualidade das águas e os padrões de lançamento de efluentes. Caso ocorra o descarte inadequado do ES é possível que cause significativos impactos no meio ambiente. Durante muitos anos resíduos suinícolas foram gerados e descartados in natura, resíduos que afetam diretamente na qualidade do solo, uma vez que contém altas concentrações de demanda bioquímica de oxigênio (DBO), sólidos em suspensão e nutrientes que representam fonte de fertilizantes, o que no entendimento dos leigos, o solo possui capacidade ilimitada de absorção desses compostos (TONIAZZO et al., 2018)

A poluição por dejetos suínos pode ser por fonte pontual ou difusa; nos dois casos ocorre o risco de poluição de águas superficiais e profundas, ou seja, a fonte pontual é aquela que pode identificar o local específico que ocorreu a poluição, por exemplo, instalações de suínos e locais de armazenamentos de dejetos, mas quando ocorre o lançamento de dejetos suínos em grandes áreas, a poluição pode ser considerada como fonte difusa, já que não é possível identificar o lugar específico que ocorreu a contaminação (GEBLER et al., 2011).

As lagoas de estabilização são um dos métodos mais simples e eficientes de tratamento de ES, podendo ser utilizadas em águas residuárias domésticas ou industriais (ARAUJO, 2016). Através dos processos físico-químicos, bioquímicos e biológicos, ocorre à transformação de compostos orgânicos em compostos minerais, ou orgânicos estáveis, e a remoção de micro-organismos patogênicos (MATTOS et al., 2010). Devido ao seu baixo custo de implantação e manutenção, as lagoas de estabilização são muito utilizadas na suinocultura. Porém, esse sistema necessita do uso de grandes áreas para sua implementação, o que acaba sendo uma desvantagem do sistema (SILVA et al., 2009). 
Utilização da taboa (typha domingensis) e papiro (cyperus papyrus) em leitos cultivados com efluente suíno originário da biodigestão anaeróbia e

FATOBENE, G.; SOTO, F. R. M.; RODRIGUES, R. A.; AGUIAR, A. C. S. V. C.

O tratamento do ES é realizado através de três tipos de lagoas: lagoas anaeróbias, lagoas facultativas e lagoas aeróbias. Lagoas anaeróbias são utilizadas como unidade primária, pois são capazes de estabilizar o ES com alta carga orgânica e podem ser associadas a biodigestores, com a produção de biogás. Na ausência de oxigênio há a fermentação dos compostos orgânicos pelas bactérias facultativas e anaeróbias estritas, gerando a diminuição do DBO e demanda química de oxigênio (DQO). Lagoas facultativas são utilizadas como tratamento secundário, pois funcionam com uma carga orgânica menor que as anaeróbias, propiciando a criação de três camadas na lagoa: região superficial prevalece plantas e algas realizando fotossíntese, na intermediária os micro-organismos anaeróbios facultativos e na do fundo os micro-organismos anaeróbios estritos. Lagoas aeróbias são utilizadas como tratamento final, pois melhoram a qualidade do ES, favorecendo a diminuição de organismos patogênicos, fósforo, nitrogênio, sólidos em suspensão e menor intensidade de DQO e DBO (MELO et al., 2013). O gênero Typha e Cyperus possuem distribuição cosmopolita, sendo encontrados em ambos hemisférios nas regiões temperadas e tropicais (MENDONÇA et al., 2015). Plantas com grande poder econômico, suas folhas e hastes servem para a produção de pasta de papel e também com função ornamental, devido à alta concentração de celulose, muito usada também na fabricação de esteiras, chapéus, cestas e sandálias, o que faz ser uma das grandes fontes de rendas no meio rural (SANTOS, 2016).

A adoção da taboa e do papiro para o tratamento de efluentes com função biorremediadora tem apresentado resultados satisfatórios (SALES FILHO et al., 2015). O uso das macrófitas aquáticas em associação ao biofilme microbiano que se forma em suas raízes tem efeito direto ou indireto na remoção dos poluentes (OLIVEIRA et al., 2016). Neste processo, o efluente ao entrar em contato com a superfície do substrato, rizomas e raízes depuram o $E S$, devido à presença do biofilme microbiano que decompõe a matéria orgânica que se encontra no local (DINIZ et al., 2005). O consumo de matéria orgânica também é realizado por meio da oxidação em decorrência dos rizomas das plantas por difusão do ar atmosférico na superfície, o que possibilita a formação de sítios aeróbios e anaeróbios no leito de escoamento de água residuária (SARCO et al., 2017).

Este trabalho teve por objetivo geral, avaliar os parâmetros físico-químicos e microbiológicos do ES originário da biodigestão anaeróbia e decantação com a utilização de Taboa (Typha domingensis) e Papiro (Cyperus papyrus) em leitos cultivados experimentais. Dentre os objetivos específicos estes foram: avaliar parâmetros físico-químicos ( $\mathrm{pH}$, sólidos totais, $\mathrm{DQO}$, nitrogênio total e fósforo total) e microbiológicos (coliformes totais e termotolerantes).

\section{MATERIAIS E MÉTODOS}

O experimento foi realizado no Instituto Federal de Educação, Ciência e Tecnologia de São Paulo, Campus São Roque (IFSP-SRQ). Foram construídos quatro sistemas experimentais com duas repetições cada um, sendo: a) tratado (taboa), b) tratado (papiro), c) tratado (papiro e taboa), e, d) controle (somente o efluente). Os sistemas foram constituídos por leitos cultivados experimentais a base de polivinil propileno 
Utilização da taboa (typha domingensis) e papiro (cyperus papyrus) em leitos cultivados com efluente suíno originário da biodigestão anaeróbia e decantação

FATOBENE, G.; SOTO, F. R. M.; RODRIGUES, R. A.; AGUIAR, A. C. S. V. C.

com capacidade para 20L, constituídos por uma camada de pedra (brita nㅇ) e uma de areia fina com microbiota estabelecida, na qual foram adicionadas as respectivas plantas, e foi definido um período de aproximadamente 30 dias para a adaptação das macrófitas nos diferentes sistemas experimentais. 0 efluente tratado foi coletado por meio de uma torneira hidráulica acoplada na parte inferior do sistema. 0 ES, papiro e taboa foram obtidos de uma granja de suínos tecnificada de ciclo completo, localizada no município de Ibiúna (SP), originário da biodigestão anaeróbia e decantação. 0 tempo de detenção hidráulica do ES foi de sete dias com despejos semanais. Os parâmetros físico-químicos avaliados foram: pH, sólidos totais (ST), nitrogênio total (NT) e fósforo total (FT), onde foram efetuadas coletas semanais (a cada sete dias) e uma no dia zero do experimento.

As análises de sólidos totais foram realizadas em duplicata utilizando-se o método 2540 B de APHA et al. (2012). A concentração de nitrogênio total (NT) foi obtida por meio do Método de Digestão por Persulfato LR (0,5 até 25,0 mg/L N), em um Espectofotômetro Hach DR/3900, com o uso de reagentes da Hach Company ${ }^{\circledR}$ (Total Nitrogen Persulfate, Reagente Powder Pillow ${ }^{\circledR}$, Total Nitrogen Hydroxide Reagent ${ }^{\circledR}$ ) em um tubo de Test ' $N$ Tube de NT. A técnica consiste em adicionar uma alíquota de $2 \mathrm{~mL}$ da amostra de ES e $2 \mathrm{~mL}$ de água destilada (como o branco), estas digeridas em um bloco aquecedor à 105ㄷ $\mathrm{C}$ por 30 minutos. Após o resfriamento, foi adicionado o reagente A chamado Total Nitrogen (TN) Reagent A Powder Pillow ${ }^{\circledR}$. Novamente, após três minutos foi adicionado o reagente B chamado Total Nitrogen (TN) Reagent B Powder Pillow $^{\circledR}$ e agitado por 15 segundos. Neste momento as amostras devem ficar com a cor amarelada. Por fim, foram transferidos $2 \mathrm{~mL}$ de amostra do ES e da amostra do branco para o terceiro tubo de Test ' $\mathrm{N}$ Tube que continha o reagente $C$ chamado Total Nitrogen (TN) Reagent $C^{\circledR}$, e a cor amarelada tendia a ficar intensificada. Por fim foi determinada a concentração de NT em cada amostra (mg/L).

O fósforo total foi determinado através do Método de molibdovanadato com Digestão de persulfato ácido HR (1.0 a 100.0 mg/PO4. 3-), em Espectofotômetro Hach DR/3900. Para determinação da concentração de FT foi adicionado $5 \mathrm{~mL}$ da amostra de ES no tubo do próprio kit, que foi agitado durante 30 segundos, e para a amostra do branco adicionou-se $5 \mathrm{~mL}$ de água destilada. Após isso, as amostras foram inseridas no reator aquecido a 150 ㅇ durante 30 minutos, e após chegarem à temperatura ambiente (18 25 으), adicionou-se $2 \mathrm{~mL}$ de hidróxido sódio $1.54 \mathrm{~N}$, e $0,5 \mathrm{~mL}$ do reagente de molibdovanadato (metavanadato de amônio, ácido sulfúrico e molibdato de amônio). Aguardou-se sete minutos para acontecer a reação colorimétrica (a formação de composto amarelo, vanadomolibdofosfórico) e em seguida os tubos foram inseridos no compartimento do Espectofotômetro HACH DR/3900 para determinação das concentrações de FT da amostra do branco e da amostra do efluente suíno em $\mathrm{mg} / \mathrm{L}$, no comprimento de onda $420 \mathrm{~nm}$. Os cálculos foram realizados comparando o resultado do padrão com o das amostras (FISKE et al., 1925). Foram também investigados os parâmetros microbiológicos, pesquisa de coliformes totais (CT) e coliformes termotolerantes, utilizando a técnica dos tubos múltiplos (VANDERZANT et al., 1992; SILVA et al., 2007). 
Utilização da taboa (typha domingensis) e papiro (cyperus papyrus) em leitos cultivados com efluente suíno originário da biodigestão anaeróbia e decantação

FATOBENE, G.; SOTO, F. R. M.; RODRIGUES, R. A.; AGUIAR, A. C. S. V. C.

\section{RESULTADOS}

Tabela 1: estão apresentados os resultados das análises de $\mathrm{pH}$ realizadas nos sistemas de cultivo de ES, tratados e controle.

\begin{tabular}{|l|l|l|l|l|l|}
\hline \multirow{2}{*}{ Leito } & \multicolumn{5}{|l|}{} \\
\cline { 2 - 6 } & Semana 0 & Semana I & Semana II & Semana III & Semana IV \\
\hline 1 & 7,71 & 7,00 & 7,62 & 7,62 & 7,65 \\
\hline 2 & 7,71 & 7,49 & 7,39 & 7,67 & 8,01 \\
\hline 3 & 7,71 & 7,32 & 7,66 & 7,77 & 7,66 \\
\hline 4 & 7,71 & 7,28 & 7,60 & 7,74 & 7,98 \\
\hline 5 & 7,71 & 7,31 & 7,44 & 7,73 & 7,58 \\
\hline 6 & 7,71 & 7,51 & 7,50 & 7,72 & 7,57 \\
\hline 7 & 7,71 & 7,11 & 7,25 & 7,59 & 7,67 \\
\hline 8 & 7,71 & 8,35 & 7,27 & 7,51 & 7,73 \\
\hline
\end{tabular}

Leitos 1 e 2 (controle); 3 e 4 (Taboa - Typha domingensis), 5 e 6 (Papiro - cyperus papirus), os leitos 7 e 8 (Taboa - Typha domingensis e Papiro - cyperus papiros).

Tabela 2: estão apresentados os resultados das análises de ST realizadas nos sistemas de cultivo de ES, tratados e controle.

\begin{tabular}{|l|l|l|l|l|l|}
\hline \multirow{2}{*}{ Leito } & $(\mathrm{ST})(\mathrm{mg} / \mathrm{L})$ & \multicolumn{5}{l|}{} \\
\cline { 2 - 6 } & Semana 0 & Semana I & Semana II & Semana III & Semana IV \\
\hline 1 & 3 & 1,18 & 2,196 & 2,284 & 3,196 \\
\hline 2 & 3 & 1,596 & 1,54 & 2,064 & 2,6 \\
\hline 3 & 3 & 13,58 & 1,956 & 2,44 & 2,824 \\
\hline 4 & 3 & 1,736 & 1,984 & 2,564 & 3,06 \\
\hline 5 & 3 & 1,928 & 1,704 & 2,868 & 2,572 \\
\hline 6 & 3 & 1,968 & 1,528 & 2,452 & 2,108 \\
\hline 7 & 3 & 2,072 & 2,212 & 2,312 & 3,244 \\
\hline 8 & 3 & 2,572 & 2,204 & 3,66 & 3,552 \\
\hline
\end{tabular}

Leitos 1 e 2 (controle); 3 e 4 (Taboa - Typha domingensis), 5 e 6 (Papiro - cyperus papirus), os leitos 7 e 8 (Taboa - Typha domingensis e Papiro - cyperus papiros).

Tabela 3: estão apresentados os resultados referentes ao número de coliformes totais presentes nos leitos cultivados durante as quatro semanas avaliadas.

\begin{tabular}{|l|l|l|l|l|l|}
\hline \multirow{2}{*}{ Leitos } & Coliformes Totais (CT) (NMP/mL) & \multicolumn{4}{l|}{} \\
\cline { 2 - 6 } & Semana 0 & Semana I & Semana II & Semana III & Semana IV \\
\hline 1 & 9300 & 2300 & 1100 & 92 & 160 \\
\hline 2 & 9300 & $<230$ & 1100 & $>11000$ & $>11000$ \\
\hline 3 & 9300 & $<230$ & 1100 & 2400 & $>11000$ \\
\hline 4 & 9300 & $<230$ & 75 & $>11000$ & $>11000$ \\
\hline 5 & 9300 & $<230$ & 75 & 11.000 & $>11000$ \\
\hline 6 & 9300 & 2300 & 460 & $>11000$ & 930 \\
\hline 7 & 9300 & 720 & 4600 & $>11000$ & $>11000$ \\
\hline 8 & 9300 & 360 & 750 & 4600 & $>11000$ \\
\hline
\end{tabular}

Leitos 1 e 2 (controle); 3 e 4 (Taboa - Typha domingensis), 5 e 6 (Papiro - cyperus papirus), os leitos 7 e 8 (Taboa - Typha domingensis e Papiro - cyperus papiros).

Tabela 4: estão disponibilizados os resultados para as análises de coliformes termotolerantes, realizadas ao decorrer das quatro semanas de duração do experimento.

\begin{tabular}{|l|l|l|l|l|l|}
\hline \multirow{2}{*}{ Leitos } & Coliformes Termotolerantes (NMP/mL) & \multicolumn{4}{l|}{} \\
\cline { 2 - 6 } & Semana 0 & Semana I & Semana II & Semana III & Semana IV \\
\hline 1 & 9300 & $<230$ & 460 & $<23$ & $<23$ \\
\hline 2 & 9300 & $<230$ & 240 & $<23$ & $<23$ \\
\hline 3 & 9300 & $<230$ & 240 & $<23$ & $<23$ \\
\hline 4 & 9300 & $<230$ & 23 & 620 & $<23$ \\
\hline 5 & 9300 & $<230$ & 23 & $<23$ & $<23$ \\
\hline 6 & 9300 & 360 & 240 & $<23$ & $<23$ \\
\hline 7 & 9300 & 360 & 2400 & $<23$ & $<23$ \\
\hline 8 & 9300 & $<230$ & $<23$ & $<23$ & 210 \\
\hline
\end{tabular}

Leitos 1 e 2 (controle); 3 e 4 (Taboa - Typha domingensis), 5 e 6 (Papiro - cyperus papirus), os leitos 7 e 8 (Taboa - Typha domingensis e Papiro - cyperus papiros). 
Utilização da taboa (typha domingensis) e papiro (cyperus papyrus) em leitos cultivados com efluente suíno originário da biodigestão anaeróbia e decantação

FATOBENE, G.; SOTO, F. R. M.; RODRIGUES, R. A.; AGUIAR, A. C. S. V. C.

Tabela 5: apresenta os valores referentes a NT encontrados ao decorrer do experimento.

\begin{tabular}{|l|l|l|l|l|l|}
\hline \multirow{2}{*}{ Leitos } & \multicolumn{4}{l|}{} \\
\cline { 2 - 6 } & Semana 0 & Semana I & Semana II & Semana III & Semana IV \\
\hline 1 & 784,56 & 19,614 & 369,864 & 311,022 & 389,478 \\
\hline 2 & 784,56 & 64,446 & 123,288 & 207,348 & 417,498 \\
\hline 3 & 784,56 & 39,228 & 327,834 & 355,854 & 347,448 \\
\hline 4 & 784,56 & 84,06 & 271,794 & 367,062 & 529,578 \\
\hline 5 & 784,56 & 78,456 & 117,684 & 333,438 & 36,426 \\
\hline 6 & 784,56 & 159,714 & 184,932 & 355,854 & 53,238 \\
\hline 7 & 784,56 & 50,436 & 137,298 & 193,338 & 330,636 \\
\hline 8 & 784,56 & 372,666 & 56,04 & 151,308 & 114,882 \\
\hline
\end{tabular}

Leitos 1 e 2 (controle); 3 e 4 (Taboa - Typha domingensis), 5 e 6 (Papiro - cyperus papirus), os leitos 7 e 8 (Taboa - Typha domingensis e Papiro - cyperus papiros).

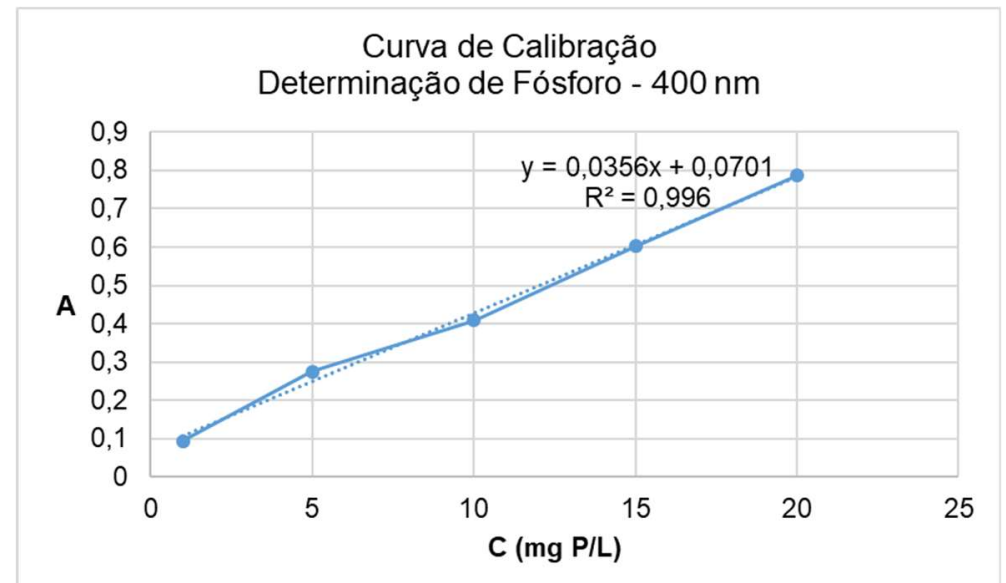

Gráfico 1: apresenta os valores Curva de calibração para determinação de fósforo a 400nm de comprimento de onda.

Tabela 6: apresenta os dados referentes as análises de fósforo total (FT), realizadas nos sistemas, durante o decorrer do experimento.

\begin{tabular}{|l|l|l|l|l|l|}
\hline \multirow{2}{*}{ Leitos } & \multicolumn{5}{l|}{ Concentração de Fósforo Total (FT) (mL.L-1) } \\
\cline { 2 - 6 } & Semana 0 & Semana I & Semana II & Semana III & Semana IV \\
\hline 1 & 113,4101 & 25,61 & 17,13 & 1,68 & 9,49 \\
\hline 2 & 113,4101 & 4,26 & 2,35 & 2,47 & 6,40 \\
\hline 3 & 113,4101 & 5,39 & 22,69 & 8,59 & 12,30 \\
\hline 4 & 113,4101 & 14,21 & 2,58 & 7,30 & 21,01 \\
\hline 5 & 113,4101 & $>1,00$ & $>1,00$ & $>1,00$ & 3,87 \\
\hline 6 & 113,4101 & 16,17 & 7,07 & 16,17 & $>1,00$ \\
\hline 7 & 113,4101 & $>1,00$ & 0,84 & 2,75 & 20,67 \\
\hline 8 & 113,4101 & 24,15 & 2,30 & $>1,00$ & 6,29 \\
\hline
\end{tabular}

Leitos 1 e 2 (controle); 3 e 4 (Taboa - Typha domingensis), 5 e 6 (Papiro - cyperus papirus), os leitos 7 e 8 (Taboa - Typha domingensis e Papiro - cyperus papiros).

\section{DISCUSSÃO}

Os valores de pH encontrados para a semana zero (efluente bruto) estão relacionados às análises de uma amostra padrão, utilizada como parâmetros para comparação e análise da evolução dos resultados. Os valores encontrados para o $\mathrm{pH}$ mantiveram-se estáveis em torno de sete, entretanto apresentando leve alcalinidade e aumento do $\mathrm{pH}$ no decorrer das semanas. Tanto a taboa quanto o papiro apresentaram resultados semelhantes, entre 7,28 e 7,98 (Leitos 3, 4, 5 e 6). Resultados de Meirelles (2017) com leitos cultivados com taboa, os resultados de pH ficaram entre 7,42 e 7,77. Resultados semelhantes também foram apresentados por Gschlöbl et al. (1998), que ao realizarem análises de leitos cultivados, observaram a mesma tendência em termos de faixa de $\mathrm{pH}$ (próximos à neutralidade). 
Utilização da taboa (typha domingensis) e papiro (cyperus papyrus) em leitos cultivados com efluente suíno originário da biodigestão anaeróbia e

Os ST são correspondentes às impurezas presentes na água (soma da matéria orgânica com a matéria inorgânica), levando em consideração o tamanho das partículas pode ser classificado como sólidos suspensos ou sólidos dissolvidos (JUST, 2010). Os teores de ST apresentaram diminuição dos valores em mg/L do início ao término do experimento, entretanto quando analisadas separadamente, as semanas I e II, apresentaram níveis significativos na diminuição dos sólidos, porém as semanas III e IV, foi possível analisar um pequeno nível de aumento nos ST. Estes resultados foram diferentes dos apresentados por Salviato (2013) e Meirelles (2017), que obtiveram redução contínua em todas as amostras realizadas.

Por definição, o grupo CT inclui bactérias das quais são gram-negativas não esporuladas, fermentadoras de lactose, que apresentam produção de ácido e gás durante o processo fermentativo e que atuam em temperatura variável entre 32ㄷ e 37으 (TOWNSEND et al., 1998). Ao realizar as análises foi possível perceber um aumento nas bactérias do grupo coliforme, contudo, o leito 1 (leito do grupo controle) apresentou constante diminuição nos níveis de $\mathrm{CT}$ durante a realização da pesquisa. $\mathrm{O}$ aumento das bactérias do grupo CT pode ser explicado pela formação do biofilme microbiano, associado as raízes das plantas, que por sua vez pode auxiliar na biorremediação do efluente suíno (XAVIER et al., 2003).

Resultados opostos ao de Calijuri et al. (2009), onde, em sua pesquisa foi possível analisar a diminuição dos níveis de CT em Wetlands e também em reatores UASB, onde atingiram uma média entre 99,20\% e 99,79\% de remoção de CT. Entretanto ainda não existem modelos consolidados de estimativas de decaimento bacteriano em leitos cultivados (RIVERA et al., 1995; USEPA, 1988; KHATIWAD et al., 1999; KADLEC et al., 2000; KARIM et al., 2004).

Os coliformes termotolerantes são constituintes de um subgrupo dos coliformes totais, cujo habitat é o trato intestinal dos animais homeotérmicos e que, do ponto de vista sanitário, podem apresentar risco ambiental, por serem bactérias potencialmente patogênicas (JORDANO et al., 1995). Os níveis de coliformes termotolerantes apresentaram constante diminuição ao decorrer do experimento, decaindo de valores inferiores a $230 \mathrm{NMP} / \mathrm{mL}$ para valores inferiores a $23 \mathrm{NMP} / \mathrm{mL}$ de amostra, apenas o leito de número 8 (pertencente ao grupo tratado com ambas as macrófitas) apresentou um aumento significativo nos valores durante a quarta semana de experimento.

Para Calijuri et al. (2009), os resultados de coliformes termotolerantes, também apresentaram diminuição durante a realização do experimento realizado em Viçosa- MG com variações nos tempos de detenção hidráulica. As macrófitas tendem a trabalhar com a remoção dos nutrientes dos efluentes incorporando-os a sua biomassa, diminuindo os teores presentes no efluente já tratado (BIUDES et al., 2008).

Todos os sistemas apresentaram redução nos teores de NT entre a semana 0 e semana 1, com níveis iniciais de 784,56 mL.L-1 e um valor mínimo de 19,614 referente ao leito 1, (grupo controle). Entretanto após a primeira semana os leitos começaram a apresentar um rápido aumento nos níveis de NT, retornando aos níveis de aproximadamente 300 ml.L-1. Apresentando remoção de NT entre 53,66\% para os leitos de controle e tratados com taboa e $94,28 \%$ para os leitos tratados exclusivamente com papiro. Os leitos tratados com ambas as macrófitas apresentaram eficiência de $71,60 \%$. 
Para Valentim (2003), a remoção de NT ficou entre 60 e 70\% durante seu período de experimento, variando a taxa de assimilação de acordo com a época do ano, nos meses mais frios o índice de absorção de nutrientes tende a diminuir em relação aos níveis relativos ao período de calor. O fósforo assim como o nitrogênio possui grande importância uma vez que é um dos principais macronutrientes para o desenvolvimento das plantas, especialmente para as macrófitas (CAMARGO et al., 2003).

O grupo controle (leitos 1 e 2) foi capaz de remover 92,99\%, o grupo tratado com taboa (leitos 3 e 4) obtiveram eficiência de remoção de $85,31 \%$, tratado apenas com papiro (leitos 5 e 6) aproximadamente $98 \%$ de eficiência de remoção de $\mathrm{FT}$, entretanto o grupo com a presença das duas macrófitas (leitos 7 e 8 ) eficiência de $88,11 \%$. As macrófitas tem apresentado potencial de remoção de nutrientes, principalmente o fósforo, potencial do qual gira entre 35\% e 48\% (BRASIL, 2005), entretanto para Silva et al. (2004) esses valores giram em torno de $80 \%$ a $90 \%$.

\section{CONCLUSÕES}

Com base nos resultados obtidos ao decorrer do experimento é possível concluir-se que os sistemas de cultivo de efluente suíno proveniente da biodigestão anaeróbia e decantação tratados com taboa (Typha domingensis) e papiro (Cyperus papirusl) não foi capaz de reduzir as bactérias do grupo coliforme total, entretanto as bactérias do grupo coliforme termotolerantes, importantes bactérias indicadoras de qualidade ambiental, apresentaram redução em todos os sistemas analisados.

Durante todo o período investigado a variação de $\mathrm{pH}$ foi mínima, mantendo-se na faixa da alcalinidade, assim como os valores de sólidos totais, que apresentaram pequena variação, por conta da forma adotada para coleta das amostras, forma da qual, tendia a liberar altas quantidades de areias nos vasos amostrais. O nitrogênio total obteve redução significativa na primeira semana do experimento, semana da qual as plantas apresentaram visualmente maiores taxas de crescimento, entretanto nas demais semanas os valores de nitrogênio total voltaram a aumentar, ainda assim, mantendo-se na faixa padrão dos demais estudos

Os valores de fósforo total apresentaram altas taxas de remoção, o papiro atuando sozinho apresentou melhor capacidade de assimilação de nutriente, possivelmente pelos menores níveis de competitividade. Demonstrando-se dessa forma um sistema com potencial de aplicação em larga escala, entretanto torna-se necessário a realização de mais estudos na área, comprovando a eficiência das macrófitas nos sistemas de leitos cultivados.

\section{REFERÊNCIAS}

APHA. American Public Health Association; AWWA. American Water Works Association; WEF. Water Enviroment Federation. Standard Methods for the Examination of water and wastewater. 22 ed. 2012.

ANUNCIATO, K. M.; PAES, N. L.. Panorama da Cadeia Produtiva da Suinocultura no Estado de Mato Grosso. Revista de Estudos Sociais, v.18, n.36, p.107-140, 2016.
ARAUJO, G. M.; LIMA I. E. N.; ARAÚJO A. L. C.; SILVA M. E. R.. Avaliação experimental e modelagem matemática de filtros anaeróbios como alternativa de baixo custo para remoção de algas de efluentes de lagoas de estabilização. Engenharia Sanitária Ambiental, v.1, n.10, p.22- 32, 2016. 
Utilização da taboa (typha domingensis) e papiro (cyperus papyrus) em leitos cultivados com efluente suíno originário da biodigestão anaeróbia e decantação

FATOBENE, G.; SOTO, F. R. M.; RODRIGUES, R. A.; AGUIAR, A. C. S. V. C.

BRASIL, M. S.. Desempenho de sistema alagado construído para tratamento de esgoto doméstico. Tese (Doutorado em Engenharia Agrícola) - Universidade Federal de Viçosa, 2005.

BIUDES, J. F. V; CAMARGO, A. F. M.. Estudos dos fatores limitantes à produção primária por macrófitas aquáticas no Brasil. Oecologia Brasiliensis, v.12, n.1, p.2, 2008.

BROETTO, T.; TORNQUIST C. G.; WEBER E. J.; CAMPOS B. H. C.; MERTEN C. G.; SCHNEIDER J. C.. Indicadores geoespaciais para avaliação do impacto ambiental da suinocultura no licenciamento em âmbito municipal. Pesquisa Agropecuária Brasileira, Brasília, v.50, n.12, p.1177-1185, 2015.

CAMARGO, A. F. M; PEZZATO, M. M.; HENRY-SILVA, G. G.. Fatores limitantes à produção primária de macrófitas aquáticas. In: THOMAZ, S. M.; BINI, L. M.. Ecologia e manejo de macrófitas aquáticas. Maringá: EDUEM, p.85-126. 2003.

CERETTA, C. A.; LORENSINI, F.; BRUNETTO, G.; GIROTTO, E.; GATIBONI, L. C.; LOURENZI, C. R.; TIECHER, T. L.; CONTI, L.; TRENTI, G.; MIOTTO, A.. Frações de fósforo no solo após sucessivas aplicações de dejetos de suínos em plantio direto. Pesquisa Agropecuária Brasileira, v.45, n.6, p.593-602, 2010.

DINIZ, C. R.; CEBALLOS, B. S. O.; BARBOSA, J. E. L.; KONING, A.. Uso de macrófitas como solução ecológica para melhoria da qualidade de água. Revista Brasileira de Economia Agrícola e Ambiental, Campina Grande, v.9, p.226-230, 2005.

FISKE, C. A.; SUBBAROW, I.. The colorimetric determination of phosphorus. Journal Biology Chemical, v.66, p.375, 1925.

GEBLER, L.; BELLO FILHO, F.. Introduzindo critérios de risco em modelos de contaminação pontual para locais de carga de agrotóxicos. Pesticidas: Revista de Ecotoxicologia e Meio Ambiente, v.21, p.85-94, 2011.

GSCHLÖBL, T.; STEINMANN, C.; SCHLEYPEN, P.; MELZER, A.. Constructed AAC for effluent polishing of lagoons. Water Research, v.32, p.2639-2645, 1998.

JORDANO, R.; LOPEZ, C.; RODRIGUEZ, V.; CORDOBA, G.; MEDINA, L. M.; BARRIOS, J.. Comparison of Petrifilm method to conventional methods for enumerating aerobic bacteria, coliforms, Escherichia coli and yeasts and molds in foods. Acta Microbiol Immunol Hung 1995; 42:255-9.

JUST, M. C.. Avaliação quantitativa e qualitativa da água de irrigação em lavouras de arroz: o caso estudo da associação de irrigação e drenagem Santo Isidoro na região sul de Santa Catarina. Dissertação (Mestrado) - Universidade do Extremo Sul Catarinense, 2010.

KADLEC, R.; KNIGHT, R.; VYMAZAL, J.; BRIX, H.; COOPER, P.; HABERL, R.. Constructed wetlands for pollution control: Processes, performance, design and operation. London: IWA Publishing, 2000.

KARIM, M. R.; MANSHADI, F. D.; KARPISCAK, M. M.; GERBA, $C$.. The persistence and removal of enteric pathogens in constructed wetlands. Water Research, v.38, n.7, p.18311837, 2004.
KHATIWAD, N. R.; POLPRASERT, C.. Kinetics of fecal coliform removal in constructed wetlands. Water Science and Technology, v.40, n.3, p.109-115, 1999.

KUNZ, A.; HIGARASHI, M. M.; OLIVEIRA, P. A.. Tecnologias de manejo e tratamento de dejetos de suínos estudadas no Brasil. Cadernos de Ciência \& Tecnologia, v.22, n.3, p.651665, 2005.

MARÇAL, D. A.; ABREU, R. C.; CHEUNG, T. L.; KIEFER, C.. Consumo de carne suína no Brasil. Aspectos simbólicos como determinantes do comportamento. Revista de agronegócio e meio ambiente, v.9, n.4, p.989-1005, 2016.

MATTOS, A. T.; FREITAS, W. S.; LO MONACO, P. A. V.. Eficiência de sistemas alagados construídos na remoção de poluentes de águas residuárias da suinocultura. Ambiente $\&$ Água-An Interdisciplinary Journal of Applied Science, v.5, n.2, 2010.

MELO, J. F.; LINDNER, E. A.. Dimensionamento Comparativo entre Sistemas de Lagoas e de Zonas de Raízes para o Tratamento de Esgoto de Pequena Comunidade. Iniciação Científica Cesumar, v.15, n.1, p.34-40, 2013.

MEIRELLES, D.. Avaliação de um protótipo de Wetland construído para polimento final de efluente gerado em abatedouro bovino. Monografia (Graduação em Engenharia Ambiental) - Universidade Federal do Rio Grande do Sul, Lajeado, 2016.

MENDONÇA, H. V.; RIBEIRO, C. B. M.; BORGES, A. C.; BASTOS, R. R.. Sistemas Alagados Construídos em Batelada: remoção de Demanda Bioquímica de Oxigênio e regulação de $\mathrm{pH}$ no tratamento de efluentes de laticínios. Revista Ambiente \& Água, v.10, n.2, p.442-450, 2015.

OLIVEIRA, S. C.; COELHO, P. N.; SÁ, O. R.. Avaliação da eficiência do tratamento de efluentes em um abatedouro do município de Passos/MG. Revista Nacional de Gerenciamento de Cidades, v.4, n.24, p.18-27, 2016.

RIVERA, F.; WARREN, A.; RAMIREZ, E.; DECAMP, O.; BONILLA, P.; GALEGOS, E.; CALDERÓN, A.; SÁNCHEZ, J. T.. Removal of pathogens from wastewaters by the root zone method (RZM). Water Science and Technology, v.32, n.3, p.211-218, 1995

SALES, I. F.; LIMA, H. C.; SANTOS, S. M.. Tolerância da Typha domingensis a Efluente de Alta Carga Orgânica (Tolerance of Typha domingensis to Effluent with a High Organic Load). Revista Brasileira de Geografia Física, v.8, n.3, p.823-830, 2015.

SALVIATO, L. F. K.. Avaliação de um Wetlands construído para o polimento de efluentes gerados por uma vinícola na região da Serra Gaúcha. Monografia (Graduação em Engenharia Ambiental) - Universidade Federal do Rio Grande do Sul, Lajeado, 2013.

SANTOS, B. S.; COSTA, P. F.; EYNG, E.; CÂMARA, C. D.. Avaliação da Eficiência de Um Sistema de Tratamento por Wetland Construído Aplicado ao Efluente de um Frigorífico de Suínos. Semina: Ciências Exatas e Tecnológicas, v.37, n.2, p.13-22, 2016. 
SARCO, D. G. C.; PAREDES, Y. E. C.; MAMANI, M. E. F.. Tratamiento de aguas residuales domesticas mediante humedales subsuperficiales con macrófita Alocasia macrorrhizos (orejas de elefante) en la urbanización los tulipanes-Chosica, Lima. Revista de Investigación Ciencia, Tecnología y Desarrollo, v.1, n.2, 2017.

SILVA, W. T. L.; NOVAES, A. P.; KUROKI, V.; MARTELLI, L. F. A.; MAGNONI JR, L.. Avaliação físico-química de efluente gerado em biodigestor anaeróbio para fins de avaliação de eficiência e aplicação como fertilizante agrícola. Química Nova, v.35, p.35-40, 2012.

SILVA, N.; JUNQUEIRA, V. C. A.; SIVEIRA, N. F. A.. Manual de métodos de análises microbiológicas de alimentos. 3 ed. São Paulo: Livraria Varela, 2007.

SOUSA, J. T.; VAN HAANDEL, A.; LIMA, E. P. C.. Use of constructed wetland for the post-treatment of domestic sewage anaerobic effluent from UASB reactor. Engenharia Sanitária e Ambiental, v.9, n.4, p.285-290, 2004.

TONIAZZO, F.; RODRIGUES, A. C.; ROSA, M. M.; ROS, C. O.; BECEGATO, V. A.; LAVNITCKi, L.; CANTONI, F.. Avaliação da liberação de $\mathrm{CO} 2$ em solo com adição de águas residuárias suinícolas e impactos ambientais e socias da suinocultura.
Revista Gestão \& Sustentabilidade Ambiental, v.7, n.1, p.253-274, 2018 .

TOWNSEND, D. E.; IRVING, R. L.; NAQUI, A.. Comparison of the SimPlate coliform and Escherichia coli test with Petrifilm, three-tube MPN, and VRBA + MUG methods for enumerating coliforms and E. coli. Food. J Food, v.61, n.4, p.444-449, 1998.

USEPA. United States Environmental Protection Agency. Manual: Constructed wetlands treatment of municipal wastewater. Cincinnati: Usepa, 2000.

VALENTIM, M. A. A.. Desempenho de leitos cultivados ('constructed wetland') para tratamento de esgoto: contribuições para concepção e operação. Tese (Doutorado em Engenharia Agrícola) - Universidade Estadual de Campinas, Campinas, 2003.

VANDERZANT, C.; SPLITTSTOESSER, D. F.. Compendium of methods for microbiological examination for foods. 3 ed. Washington: American Public Health Association, 1992.

XAVIER, J. B.; PICIOREANU, C.; ALMEIDA, J. S.; VAN LOOSDRECHT, M. C. M.. Monitorização e modelação da estrutura de biofilmes. Boletim de Biotecnologia, v.76, n.1, p.2-13, 2003.

A CBPC - Companhia Brasileira de Produção Científica (CNPJ: 11.221.422/0001-03) detém os direitos materiais desta publicação. Os direitos referem-se à publicação do trabalho em qualquer parte do mundo, incluindo os direitos às renovações, expansões e disseminações da contribuição, bem como outros direitos subsidiários. Todos os trabalhos publicados eletronicamente poderão posteriormente ser publicados em coletâneas impressas sob coordenação da Sustenere Publishing, da Companhia Brasileira de Produção Científica e seus parceiros autorizados. Os (as) autores (as) preservam os direitos autorais, mas não têm permissão para a publicação da contribuição em outro meio, impresso ou digital, em português ou em tradução. 